\title{
A Novel Multiband Miniature Planar Inverted F Antenna Design for Bluetooth and WLAN Applications
}

\author{
J. M. Jeevani W. Jayasinghe ${ }^{1,2}$ and Disala Uduwawala ${ }^{2}$ \\ ${ }^{1}$ Department of Electronics, Wayamba University of Sri Lanka, Kuliyapitiya, Sri Lanka \\ ${ }^{2}$ Department of Electrical and Electronic Engineering, University of Peradeniya, Peradeniya, Sri Lanka \\ Correspondence should be addressed to J. M. Jeevani W. Jayasinghe; jeevani98@yahoo.com
}

Received 23 November 2014; Revised 28 January 2015; Accepted 28 January 2015

Academic Editor: Stefano Selleri

Copyright (c) 2015 J. M. J. W. Jayasinghe and D. Uduwawala. This is an open access article distributed under the Creative Commons Attribution License, which permits unrestricted use, distribution, and reproduction in any medium, provided the original work is properly cited.

\begin{abstract}
A novel compact planar inverted $\mathrm{F}$ antenna (PIFA) optimized using genetic algorithms for $2.4 \mathrm{GHz}$ (Bluetooth) and $5 \mathrm{GHz}$ (UNII-1, UNII-2, UNII-2 extended, and UNII-3) bands is presented. The patch with a shorting pin is on a $20 \times 7 \times 0.762 \mathrm{~mm}^{3}$ substrate, which is suspended in air $5 \mathrm{~mm}$ above a $30 \times 7 \mathrm{~mm}^{2}$ ground plane. Genetic algorithm optimization (GAO) is used to optimize the patch geometry, feed position, and shorting pin position simultaneously. Simulations are carried out by using HFSS and a prototype antenna is fabricated to compare the measurements with the simulations. The antenna shows fractional impedance bandwidths of $4 \%$ and $21 \%$ and gains of $2.5 \mathrm{~dB}$ and $3.2 \mathrm{~dB}$ at lower and upper bands, respectively.
\end{abstract}

\section{Introduction}

The rapid expansion in wireless communication systems creates a massive demand for novel compact multiband antennas which are integrable with other electronic components. Planar inverted F antennas (PIFA) give excellent performance when multiband operations are required in devices where there are space constraints [1]. Hence, these antennas are increasingly being used in Bluetooth and wireless local area network (WLAN) applications such as smart phones and laptops.

The Bluetooth and especially WLAN have seen a rapid growth in the recent past making it necessary to allocate more frequency bands. WLAN is recognized as a reliable and cost effective solution for wireless high speed data connectivity. The Bluetooth operates in a single frequency band, 2.4$2.483 \mathrm{GHz}$, whereas WLAN operates in the same band and another four bands in the $5 \mathrm{GHz}$ range, which are known as Unlicensed National Information Infrastructure (UNII) bands, namely, UNII-1 (5.15-5.25 GHz), UNII-2 (5.25$535 \mathrm{GHz}), \mathrm{UNII}-2$ extended (5.47-5.725 GHz), and UNII-3 $(5.725-5.825 \mathrm{GHz})$. Hence devices with these facilities must be capable of operating in all these bands leading to the need of multiband antennas.

Many compact antennas for Bluetooth and WLAN have been reported in the literature [2-14]. Some of these antennas are narrow band while some have relatively larger dimensions. There are very compact and multiband antennas designed to be integrated in laptops $[3,4]$ and mobile terminals [8]. Overall antenna volume of the PIFA, which is the smallest antenna for Bluetooth and WLAN, is $16.3 \times$ $8 \times 8 \mathrm{~mm}^{3}$ [3]. These antennas have standard geometries and multiband operation is achieved by incorporating slots, parasitic elements, capacitive loading, and shorting pins. In this paper, a very compact multiband PIFA for Bluetooth and WLAN is presented where the planar geometry and feed and shorting pin positions are obtained by using genetic algorithm optimization (GAO). GAO is a robust, stochastic-based search method, which can handle the common characteristics of electromagnetic optimization problems that are not readily handled by other traditional optimization methods $[15,16]$. GAO has been used to design broadband $[17,18]$, multiband [19-21], and miniature [22, 23] antennas. Further, radiation characteristics of antennas have been improved by using 


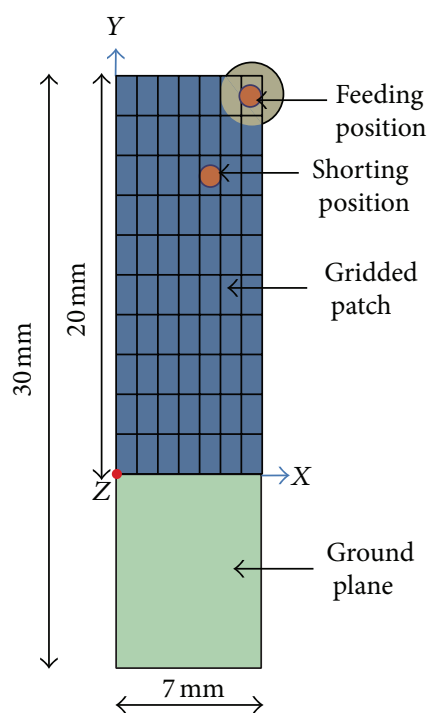

(a)

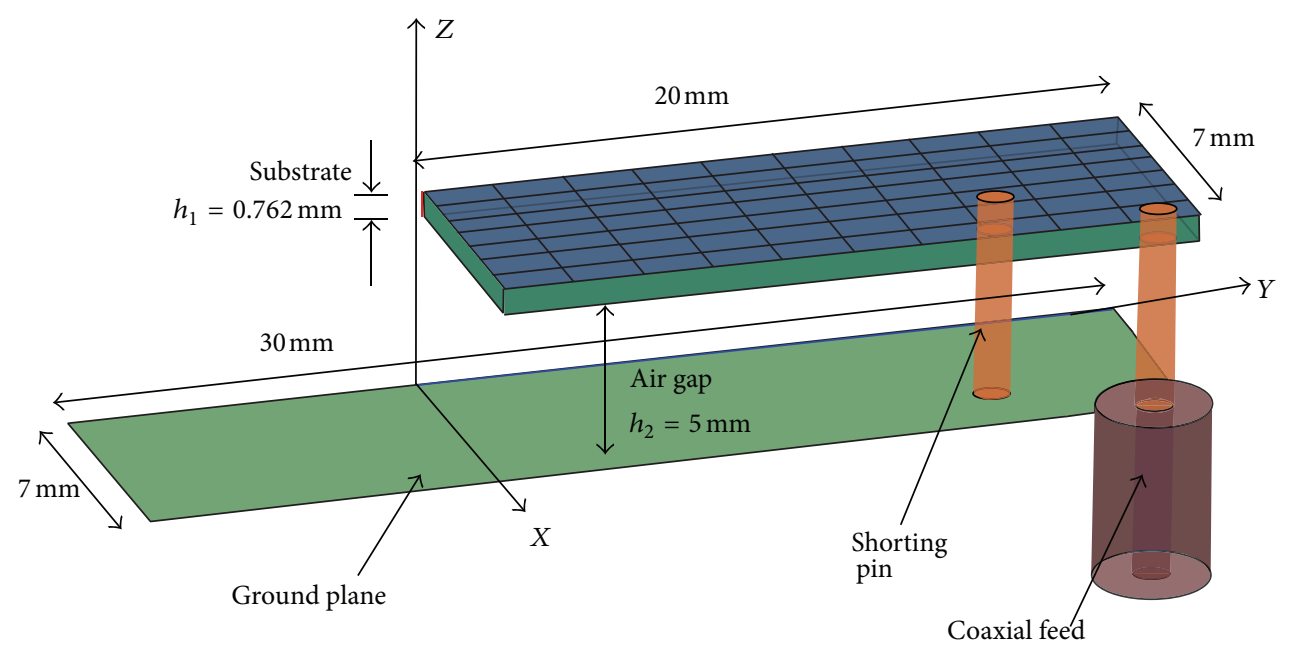

(b)

Figure 1: Antenna configuration. (a) Top view. (b) 3D view of the antenna.

GAO to obtain high directivity $[24,25]$ and broadside radiation [26].

The designed antenna has a low profile with dimensions $20 \times 7 \times 5 \mathrm{~mm}^{3}$ and is mounted on a $7 \times 30 \mathrm{~mm}^{2}$ ground plane. It can be easily placed at the border of the display of a laptop. The simulations and analysis of results are carried out by using HFSS (High Frequency Structure Simulator) from Ansoft which is a highly accurate and commercially used electromagnetic solver. A homemade GA code is used to perform optimization. The GA operation is written using Visual Basic Script (VBS) Writer and the VBS file is called into HFSS environment to perform simulations. A prototype has been built to validate the simulation results. The following sections of the paper are organized as follows. Section 2 describes the antenna configuration and GAO procedure. Section 3 presents the results of the optimization including the antenna geometry and its reflection coefficient and radiation characteristics. A comparison of simulations with the measurements taken from the prototype is also included. Finally, in Section 4, conclusions are given.

\section{Antenna Configuration and the GAO Procedure}

Figure 1 shows the antenna configuration. The optimum geometry is sought from a $20 \times 7 \mathrm{~mm}^{2}$ patch area on a substrate of the same size by dividing it into 70 cells of cell size $2 \times 1 \mathrm{~mm}^{2}$. The substrate NX9320 (IM) from Neltec has a thickness of $0.762 \mathrm{~mm}$ and a relative permittivity of 3.2. It is suspended on air $5 \mathrm{~mm}$ above a ground plane with dimensions $30 \times 7 \mathrm{~mm}^{2}$. The optimum positions of the shorting pin and feed are also sought from genetic algorithms. Therefore, the first 70 genes of the chromosome are used to define

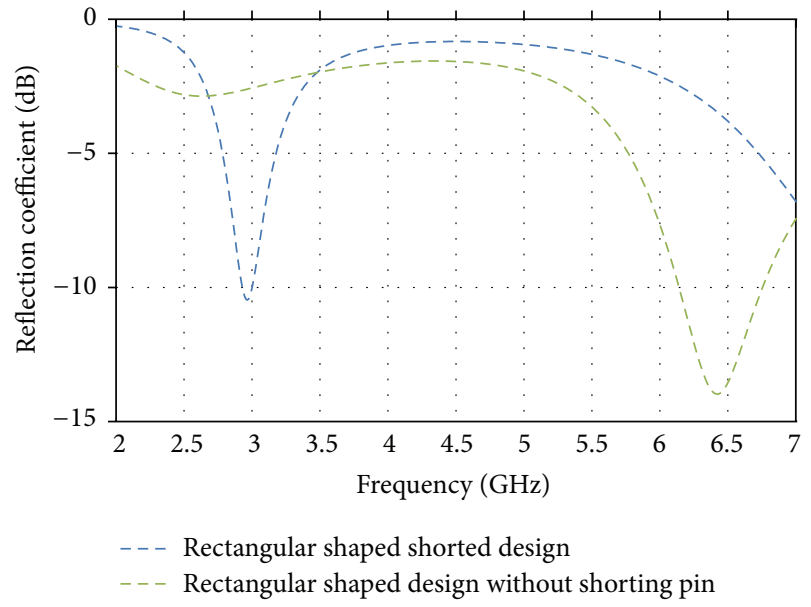

FIGURE 2: Reflection coefficient variation with frequency.

the shape and the next five and three genes are used to define the feed and shorting pin positions, respectively, in the GAO procedure. The conductivity property of each cell is defined by using "0"s and "1"s in the chromosome. Further, feed and shorting pin positions are selected out of 32 and 8 positions distributed on the patch, respectively.

Antenna with a rectangular shaped profile resonates around $6.5 \mathrm{GHz}$ (Figure 2). When a shorting pin is included, the resonant frequency reduces. However, the resonant frequency depends on the shorting position. Therefore, it is necessary to design the patch geometry and the shorting position with the help of GAO to make the antenna resonate at the required bands having sufficient bandwidths. 


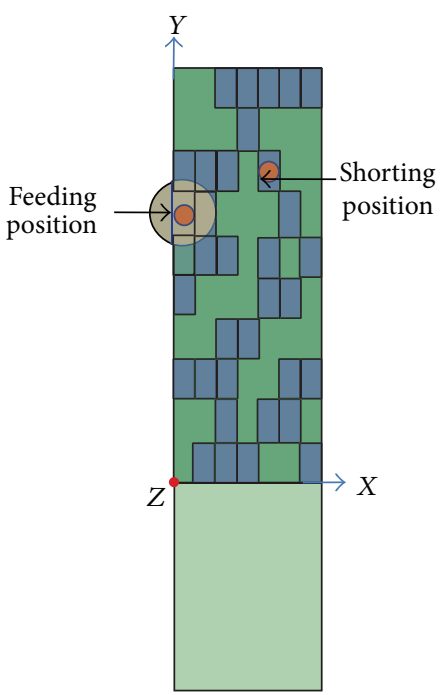

(a)

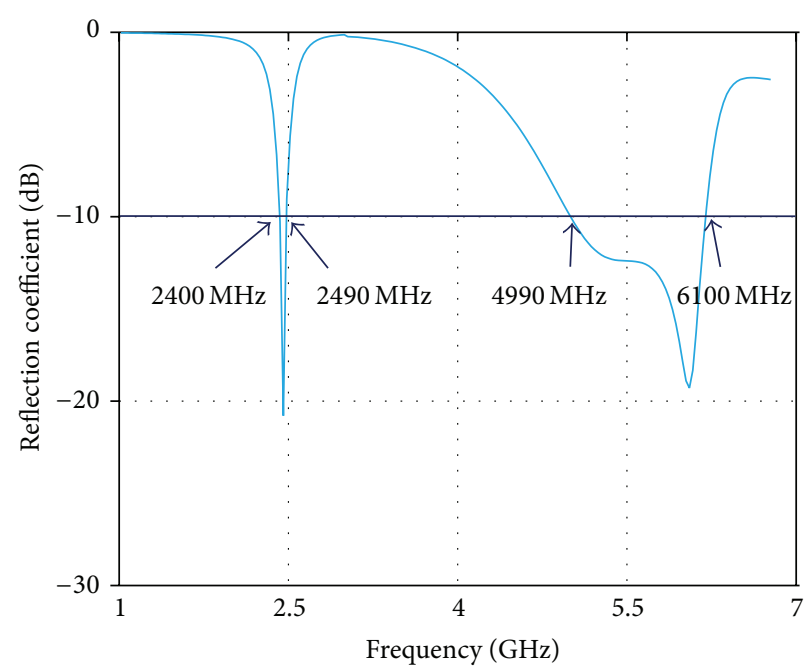

(b)

FIgURE 3: (a) Top view of the PIFA. (b) Reflection coefficient variation with frequency.

The design was aimed at obtaining at least $-10 \mathrm{~dB}$ reflection coefficient in the required frequency bands when the antenna is fed by a $50 \Omega$ coaxial line. Therefore, the fitness function is based on the summation of reflection coefficient values taken at $10 \mathrm{MHz}$ intervals including Bluetooth, UNII-1, UNII-2, UNII-2 extended, and UNII-3 bands, ranging from $f_{1}=2.4 \mathrm{GHz}$ to $f_{2}=2.5 \mathrm{GHz}$ and from $f_{3}=5.15 \mathrm{GHz}$ to $f_{4}=$ $5.85 \mathrm{GHz}$. The fitness function $F$ which is maximized in the search for the optimum solution is defined as

$$
F=\frac{-\left(\sum_{f_{i}=f_{1}}^{f_{2}} L\left(f_{i}\right)+\sum_{f_{i}=f_{3}}^{f_{4}} L\left(f_{i}\right)\right)}{10 N},
$$

where $N$ is the total number of samples $(N=82)$ and $L\left(f_{i}\right)$ is defined as

$$
L\left(f_{i}\right)=\left\{\begin{array}{cl}
\rho\left(f_{i}\right)_{\mathrm{dB}}, & \rho\left(f_{i}\right)_{\mathrm{dB}} \geq-10 \mathrm{~dB}, \\
-10 \mathrm{~dB}, & \rho\left(f_{i}\right)_{\mathrm{dB}}<-10 \mathrm{~dB},
\end{array}\right.
$$

where $\rho\left(f_{i}\right)_{\mathrm{dB}}$ is the reflection coefficient in $\mathrm{dB}$ at frequency $f_{i} . F$ is defined in such a way that wideband solutions are preferred over narrowband solutions with very low reflection coefficient values. The maximum value of $F$ is unity and it is taken as the termination criterion of the algorithm.

In the GAO procedure, a constant population size of 20 is used. The initial population is created randomly and 10 pairs are selected using tournament selection. Single point crossover is applied on each pair with mutation probability of 1\%. A temporarily expanded generation with 40 individuals is created and it consists of the current generation and its siblings. Next generation is formed from the best 20 individuals in order to ensure the preservation of the fittest.
The best fitness of each iteration is checked and simulations are done continuously until the best fitness converges.

\section{The New Design and Its Characteristics}

The optimized PIFA design and its reflection coefficient variations with frequency are shown in Figure 3. The antenna clearly resonates in two frequency bands. It has a $-10 \mathrm{~dB}$ impedance bandwidth from 2.4 to $2.49 \mathrm{GHz}$ and from 4.99 to $6.1 \mathrm{GHz}$ covering both Bluetooth and all bands of WLAN.

The current distributions in the antenna at 2.45, 5.4, and $6.0 \mathrm{GHz}$ in the lower and upper bands are shown in Figure 4 . The first frequency is at the centre of the lower band and the last two are the resonant frequencies in the upper band. The upper band is broadband and can be considered as a combination of two resonant bands. Unlike in a PIFA with a standard geometry, the current distribution of this design is quite complicated. At $2.45 \mathrm{GHz}$ in the lower band, the main current path (a-b-c-d-e-f) is approximately quarter wave length long indicating that the resonance is in the fundamental mode. The current paths at $5.4 \mathrm{GHz}$ (k-1-m-no) and $6.0 \mathrm{GHz}(\mathrm{u}-\mathrm{v}-\mathrm{w}-\mathrm{x}-\mathrm{y}-\mathrm{z})$ are approximately half- and three-quarter wavelengths long, respectively, indicating that the resonance is at higher-order modes. The wave-like current magnitude variations corresponding to the lengths of these paths are not evident due to many junctions of current paths including the shorting pin.

The radiation patterns in two orthogonal planes normal to the patch $\left(\phi=0^{\circ}\right.$ and $\left.\phi=90^{\circ}\right)$ of the antenna are shown in Figure 5. The antenna has nearly broadside radiation characteristics in both Bluetooth and UNII bands. The maximum gain values are $2.5 \mathrm{~dB}$ and $3.2 \mathrm{~dB}$ in lower and upper bands, respectively. 


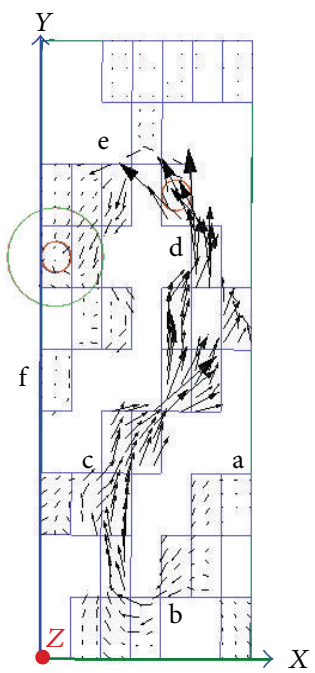

(a)

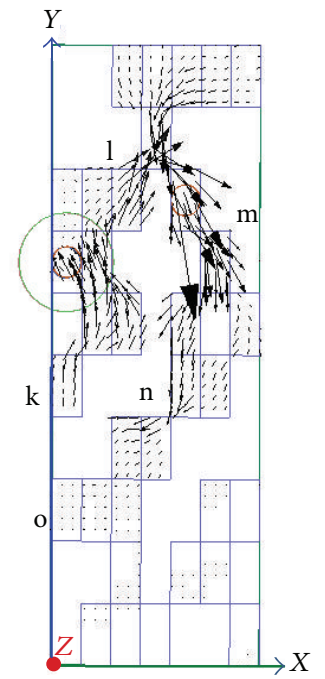

(b)

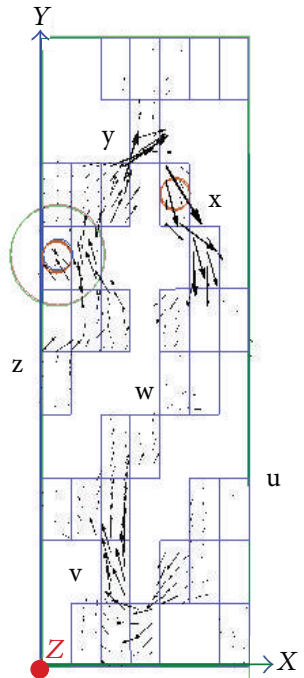

(c)

FIGURE 4: Current distributions in the patch at (a) $2.45 \mathrm{GHz}$. (b) $5.4 \mathrm{GHz}$. (c) $6.0 \mathrm{GHz}$.

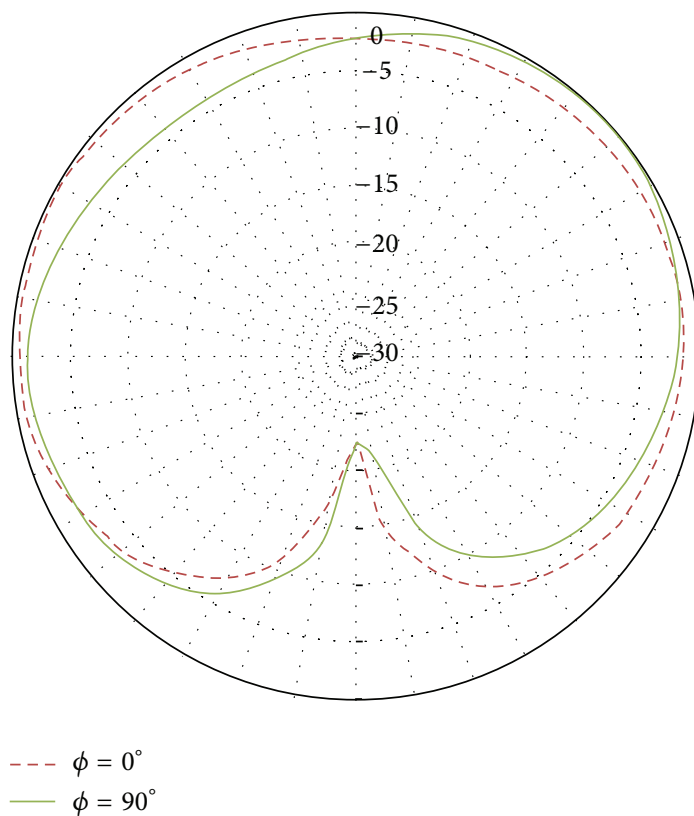

(a)

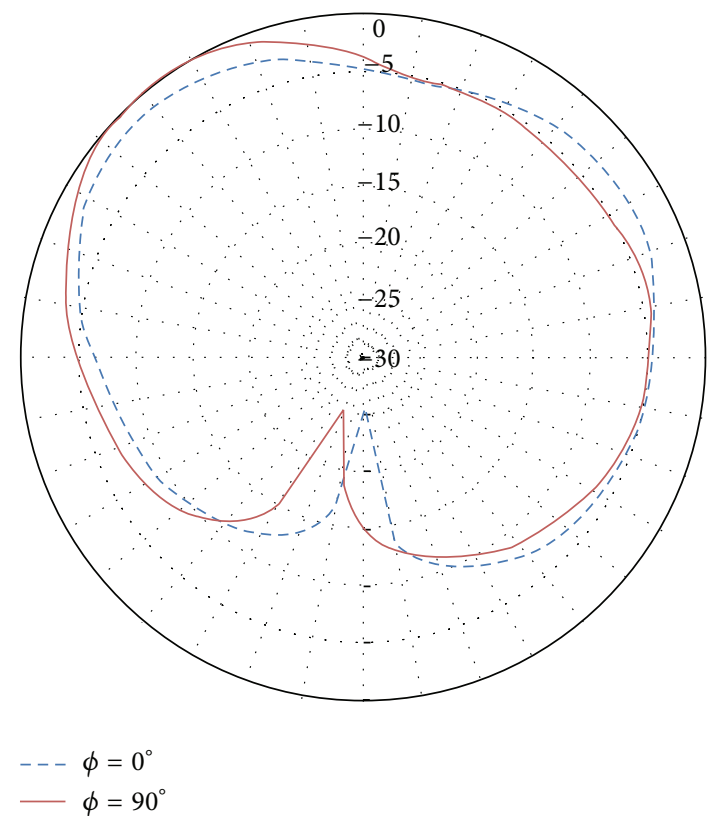

(b)

FIGURE 5: Radiation patterns at (a) $2.45 \mathrm{GHz}$. (b) $5.4 \mathrm{GHz}$.

A prototype antenna was fabricated and its reflection coefficient has been measured by using a vector network analyser. Figure 6 shows the prototype and the comparison of the measurements with simulations which are in good agreement. However, a shift in the lower frequency band can be observed due to the high sensitivity of the shorting pin. Work is in progress to check the suitability of this PIFA to be installed at the border of the display of a notebook.

\section{Conclusions}

A novel PIFA designed using genetic algorithm optimization has been described. The antenna is very compact and suitable for Bluetooth and WLAN applications in both $2.4 \mathrm{GHz}$ and $5 \mathrm{GHz}$ bands. The multiband properties were achieved with the combination of the shorting pin and the GA optimized antenna geometry, which is different from traditional shapes 


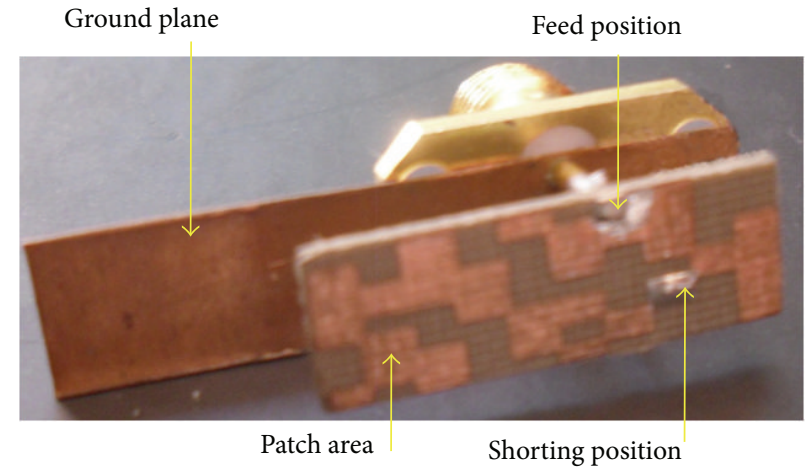

(a)

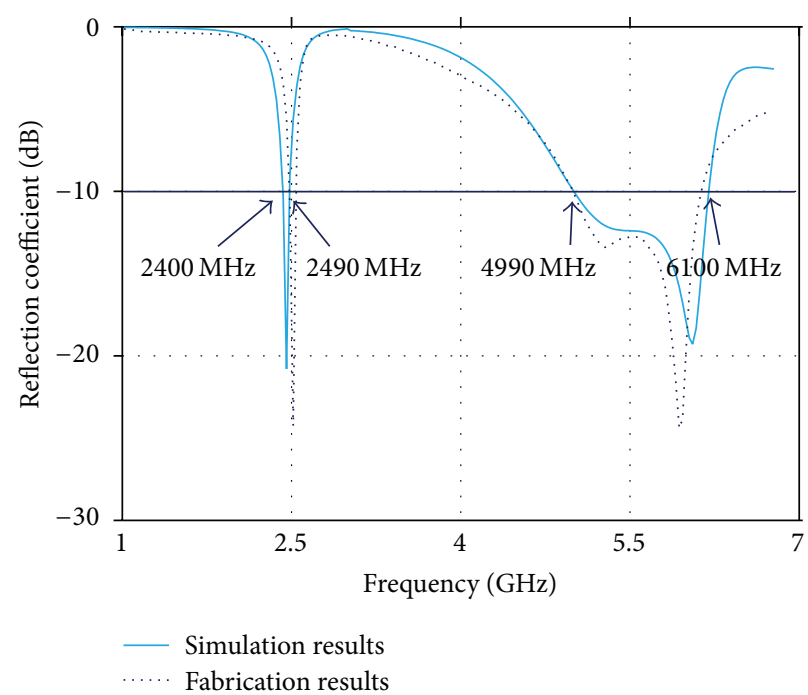

(b)

Figure 6: (a) Prototype antenna. (b) Comparison of reflection coefficient measurements with simulations.

with slots, parasitic elements, and so forth. The antenna shows $4 \%$ and $21 \%$ fractional impedance bandwidths at the narrow lower band and upper band, respectively, where the upper band has to be broader to cover several UNII bands. The antenna is nearly broadside in both bands with gains $2.5 \mathrm{~dB}$ and $3.2 \mathrm{~dB}$ at lower and upper bands, respectively. The design was simulated in HFSS and it is validated from measurements done on a prototype.

\section{Conflict of Interests}

The authors declare that there is no conflict of interests regarding the publication of this paper.

\section{Acknowledgment}

The authors acknowledge the financial support from University Grants Commission, Sri Lanka.

\section{References}

[1] K. L. Wong, Planar Antennas for Wireless Communications, John Wiley \& Sons, New York, NY, USA, 2003.

[2] A. Cáp, Z. Raida, E. de las Heras Palmero, and R. L. Ruiz, "Multiband planar antennas: a comparative study," Radioengineering, vol. 14, no. 4, pp. 11-20, 2005.

[3] P. Nepa, G. Manara, A. A. Serra, and G. Nenna, "Multiband PIFA for WLAN mobile terminals," IEEE Antennas and Wireless Propagation Letters, vol. 4, no. 1, pp. 349-350, 2005.

[4] K.-L. Wong, L.-C. Chou, and C.-M. Su, "Dual-band flat-plate antenna with a shorted parasitic element for laptop applications," IEEE Transactions on Antennas and Propagation, vol. 53, no. 1, pp. 539-544, 2005.

[5] K.-L. Wong and C.-H. Chang, "WLAN chip antenna mountable above the system ground plane of a mobile device," IEEE Transactions on Antennas and Propagation, vol. 53, no. 11, pp. 34963499, 2005.
[6] D.-U. Sim and J.-I. Choi, "A compact wideband modified planar inverted F antenna (PIFA) for 2.4/5-GHz WLAN applications," IEEE Antennas and Wireless Propagation Letters, vol. 5, no. 1, pp. 391-394, 2006.

[7] F.-R. Hsiao and K.-L. Wong, "Omnidirectional planar folded dipole antenna," IEEE Transactions on Antennas and Propagation, vol. 52, no. 7, pp. 1898-1902, 2004.

[8] H. Wang and M. Zheng, "An internal triple-band WLAN antenna," IEEE Antennas and Wireless Propagation Letters, vol. 10 , pp. 569-572, 2011.

[9] D. Nashaat, H. A. Elsadek, and H. Ghali, "Dual-band reduced size PIFA antenna with U-slot for Bluetooth and WLAN applications," in Proceedings of the IEEE International Antennas and Propagation Society International Symposium, vol. 2, pp. 962965, IEEE, June 2003.

[10] S.-H. Yeh and K.-L. Wong, "Dual-band F-shaped monopole antenna for 2.4/5.2 GHz WLAN application," in Proceedings of the IEEE Antennas and Propagation Society International Symposium, vol. 4, pp. 72-75, IEEE, June 2002.

[11] Y.-S. Shin and S.-O. Park, "A compact loop type antenna for Bluetooth, S-DMB, Wibro, WiMax, and WLAN applications," IEEE Antennas and Wireless Propagation Letters, vol. 6, pp. 320323, 2007.

[12] J.-Y. Jan and L.-C. Tseng, "Small planar monopole antenna with a shorted parasitic inverted- $\mathrm{L}$ wire for wireless communications in the 2.4-, 5.2-, and 5.8-GHz bands," IEEE Transactions on Antennas and Propagation, vol. 52, no. 7, pp. 1903-1905, 2004.

[13] M. Jung, Y. Kim, and B. Lee, "Dual frequency meandered PIFA for Bluetooth and WLAN applications," in Proceedings of the IEEE International Antennas and Propagation Symposium, vol. 2, pp. 958-961, IEEE, June 2003.

[14] M. Ali, R. A. Sadler, and G. J. Hayes, "A uniquely packaged internal inverted-F antenna for bluetooth or wireless LAN application," IEEE Antennas and Wireless Propagation Letters, vol. 1, no. 1, pp. 5-7, 2002.

[15] J. M. Johnson and Y. Rahmat-Samii, "Genetic algorithms in engineering electromagnetics," IEEE Antennas and Propagation Magazine, vol. 39, no. 4, pp. 7-21, 1997. 
[16] F. J. Villegas, T. Cwik, Y. Rahmat-Samii, and M. Manteghi, "A parallel electromagnetic genetic-algorithm optimization (EGO) application for patch antenna design," IEEE Transactions on Antennas and Propagation, vol. 52, no. 9, pp. 2424-2435, 2004.

[17] J. M. J. W. Jayasinghe and D. N. Uduwawala, "Optimization of the performance of patch antennas using genetic algorithms," Journal of the National Science Foundation of Sri Lanka, vol. 41, no. 2, pp. 113-120, 2013.

[18] H. Choo, A. Hutani, L. C. Trintinalia, and H. Ling, "Shape optimization of broadband microstrip antennas using genetic algorithm," Electronics Letters, vol. 36, no. 25, pp. 2057-2058, 2000.

[19] J. W. Jayasinghe, J. Anguera, and D. N. Uduwawala, "A simple design of multi band microstrip patch antennas robust to fabrication tolerances for GSM, UMTS, LTE, and Bluetooth applications by using genetic algorithm optimization," Progress In Electromagnetics Research M, vol. 27, pp. 255-269, 2012.

[20] M. Polivka, M. Drahovzal, J. Rohan, and P. Hazdra, "Multiband patch antenna with perturbation elements generated by genetic algorithm," in Proceedings of the European Conference on Antennas and Propagation, pp. 6-10, November 2006.

[21] J. M. J. W. Jayasinghe, D. N. Uduwawala, and J. Anguera, “Design of dual band patch antennas for cellular communications by genetic algorithm optimization," International Journal of Engineering and Technology, vol. 1, no. 1, pp. 26-43, 2012.

[22] P. Soontornpipit, C. M. Furse, and Y. C. Chung, "Miniaturized biocompatible microstrip antenna using genetic algorithm," IEEE Transactions on Antennas and Propagation, vol. 53, no. 6, pp. 1939-1945, 2005.

[23] J. W. Jayasinghe and D. N. Uduwawala, "A novel miniature multi-frequency broadband patch antenna for WLAN applications," in Proceedings of the IEEE 8th International Conference on Industrial and Information Systems (ICIIS '13), pp. 361-363, Peradeniya, Sri Lanka, December 2013.

[24] J. W. Jayasinghe, J. Anguera, and D. N. Uduwawala, "A highdirectivity microstrip patch antenna design by using genetic algorithm optimization," Progress in Electromagnetics Research C, vol. 37, pp. 131-144, 2013.

[25] J. M. J. W. Jayasinghe, J. Anguera, and D. Uduwawala, "Genetic algorithm optimization of a high-directivity microstrip patch antenna having a rectangular profile," Radioengineering, vol. 22, no. 3, pp. 700-707, 2013.

[26] J. Jayasinghe, D. Uduwawala, and J. Anguera, "Design of a genetic microstrip patch antenna with broadside radiation for GSM applications," International Journal of Scientific World, vol. 2, no. 2, pp. 84-87, 2014. 

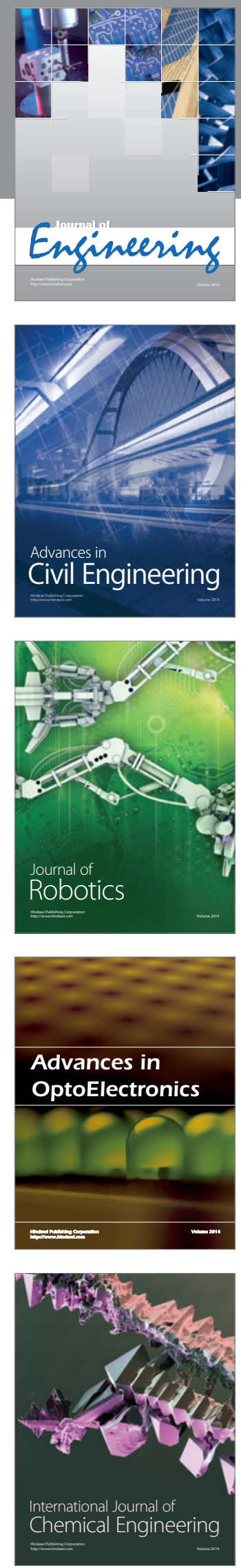

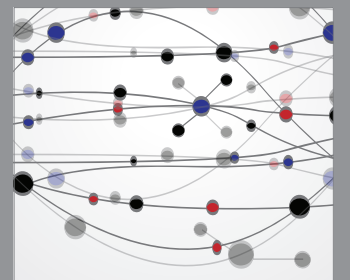

The Scientific World Journal
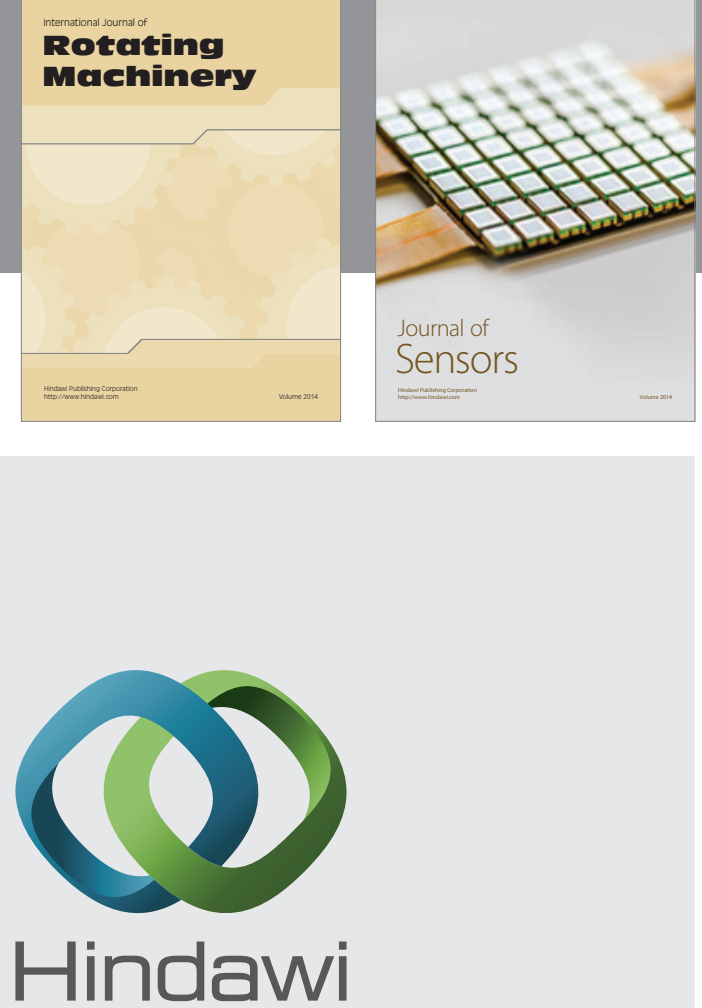

Submit your manuscripts at http://www.hindawi.com
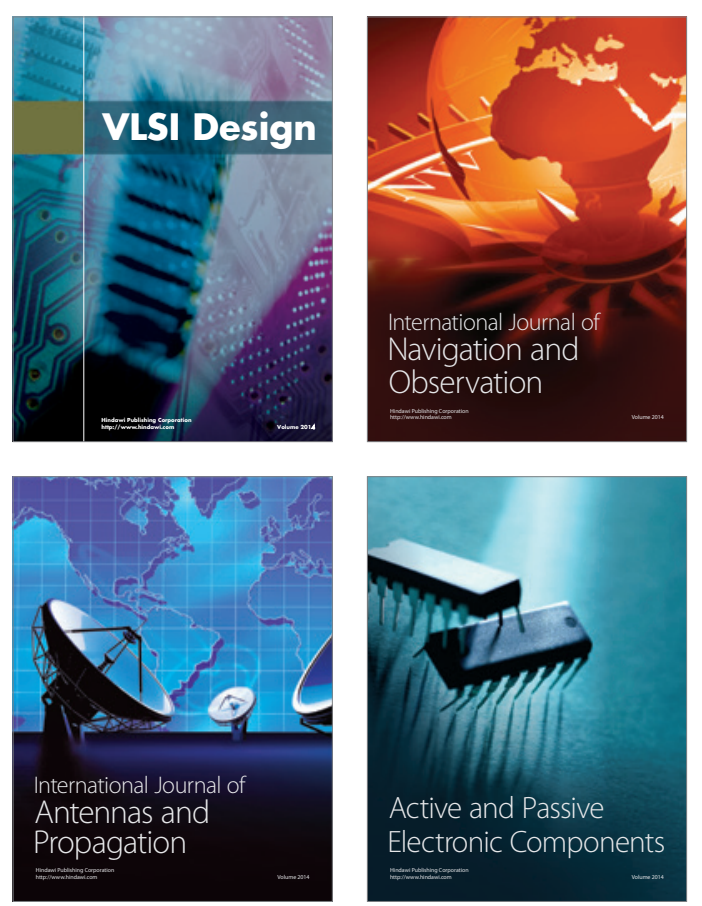
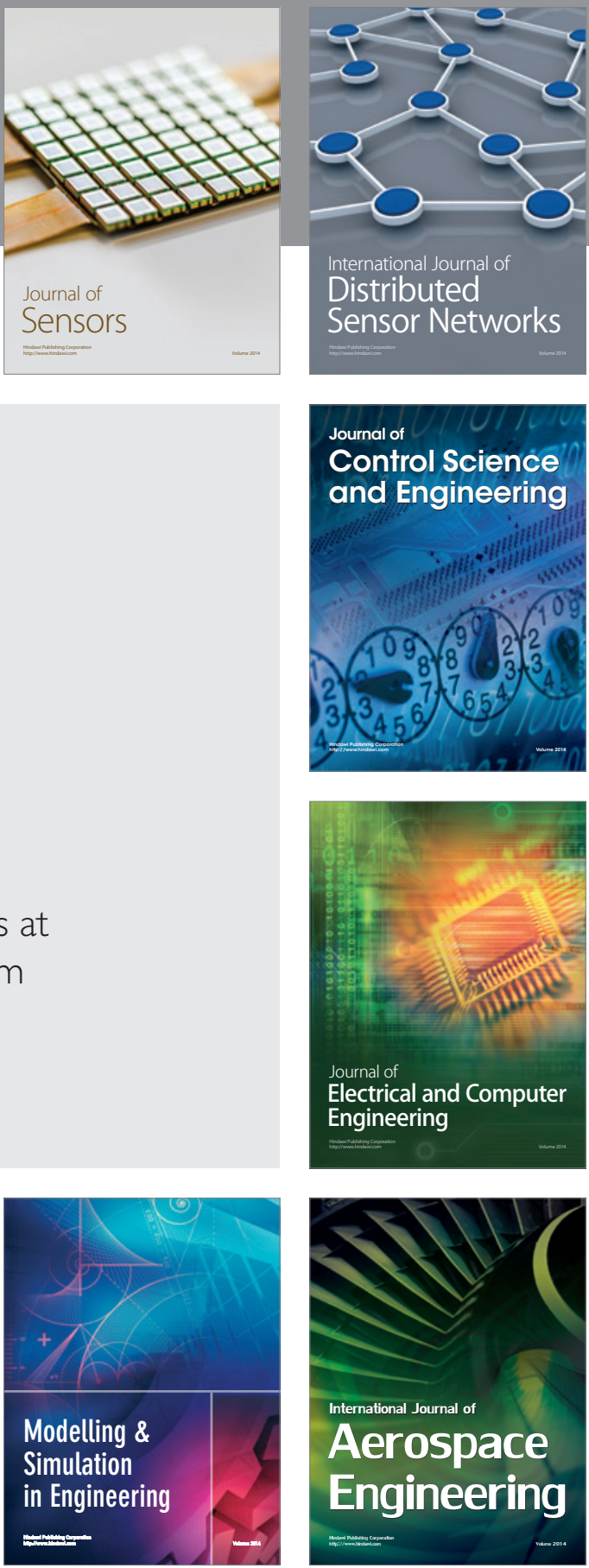

Journal of

Control Science

and Engineering
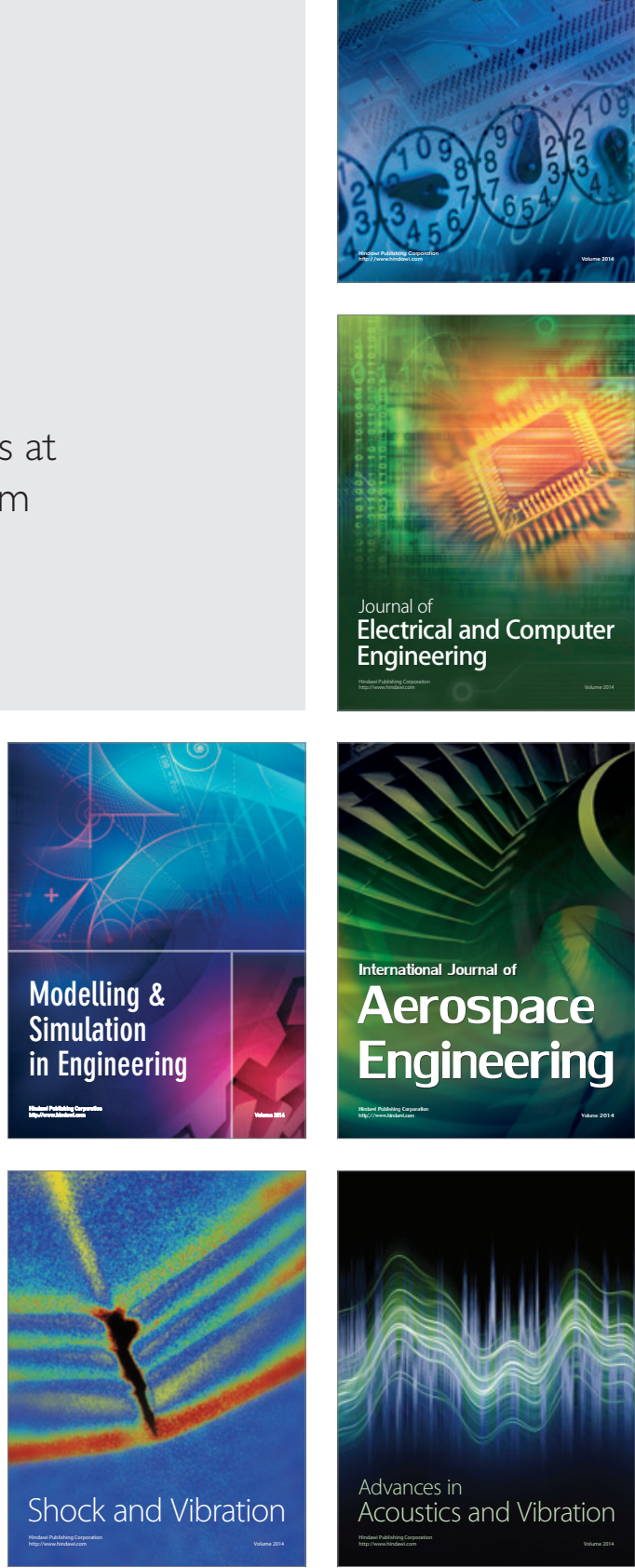